\title{
A SEM/EDS non invasive study of small portraits on copper support of the 17th and 18th centuries
}

Veiga, A. ${ }_{* * * * * * * * * *}^{* * *}$, Mirão, J. ${ }^{* *, * * * * *}$, Candeias, A. ${ }^{* * * * * *}$, Rodrigues, P. ${ }^{* * *, * * * * * *}$, Teixeira, D. M. ${ }^{* * * *}$, Teixeira, J. G. ${ }^{*}$

* Chemistry Department \& Évora Chemistry Center (CQE), University of Évora, R. Romão Ramalho, 59, 7000-671 Évora, PORTUGAL

** Geosciences Department \& Geophysics Center (CGE), University of Évora, R. Romão Ramalho, 59, 7000671 Évora, PORTUGAL

*** History Department \& Center for Art History and Scientific Research (CHAIA), University of Évora, Palácio do Vimioso, Largo Marques de Marialva, 8, 7000-809 Évora, PORTUGAL

**** Chemistry Department \& Institute of Mediterranean Agricultural and Environmental Sciences (ICAAM), University of Évora, R. Romão Ramalho, 59, 7000-671 Évora, PORTUGAL

****** HERCULES Laboratory, University of Évora, Palácio do Vimioso, Largo Marques de Marialva, 8, 7000809 Évora, PORTUGAL

Email: dinaveiga@yahoo.com

Scanning Electron Microscopy (SEM) coupled with Energy dispersive X-ray spectrometry (EDS) microanalysis is a widely used technique for the analysis and characterization of cultural heritage materials $[1,2]$. Using spectral imaging (SI) techniques (i.e., X-ray spectra for each pixel in the SEM image field) and fast silicon drift detectors, quantitative phase analysis of large areas of an object can be obtained in relatively short acquisition times.

In this work we used the SEM/EDS technique in the morphological characterization and in-situ microanalysis of small portraits on copper support of the seventeenth/eighteenth centuries. As is well known, scientific investigations of artworks using non-destructive in-situ techniques are challenging and important from the point of view of understanding of an object's history, conservation, restoration, dating and authentication [3].

The studied portraits are small oil paintings on copper that are part of the collection of portraits of the Museum of Évora (in Évora - Portugal - UNESCO World Heritage Site), which belonged mainly to the Portuguese royal family (House of Braganza). Apart the simple observation of their condition and the scant historical interpretations assigned to them, these pieces have never been studied.

Scanning electron microscopy (SEM) in combination with energy dispersive X-ray (EDX) analysis allowed us to obtain information regarding the chemical composition of the copper support (Fig. 1), and to observe the roughening of its surface (frequently created in the preparation of the plate prior to painting), the corrosion products formed on it (Fig. 2), and also the preparatory layer between the support and the pictorial layer (Fig. 3, after the surface had been roughened, it was usual to apply one or more preparatory layers, prior to painting). Detailed information concerning aging processes in these paints can be deduced from SEM backscattered-electron images. In several pieces we can observe the lead white degradation (Fig. 4). All this information was obtained in a non-invasive way, without any preparation step or sampling from the paintings or their supports.

The authors acknowledge Fundação para a Ciência e Tecnologia for the grant SFRH/BD/75549/2010. 
[1] van Hoek, C. J. G. et al., Microsc. Microanal., 17, 656-660, 2011.

[2] Schreiner, M. et al., Anal Bioanal Chem, 387, 737- 747, 2007.

[3] Clark, R. J. H., Chem. Soc. Rev., 24, 187-196, 1995.
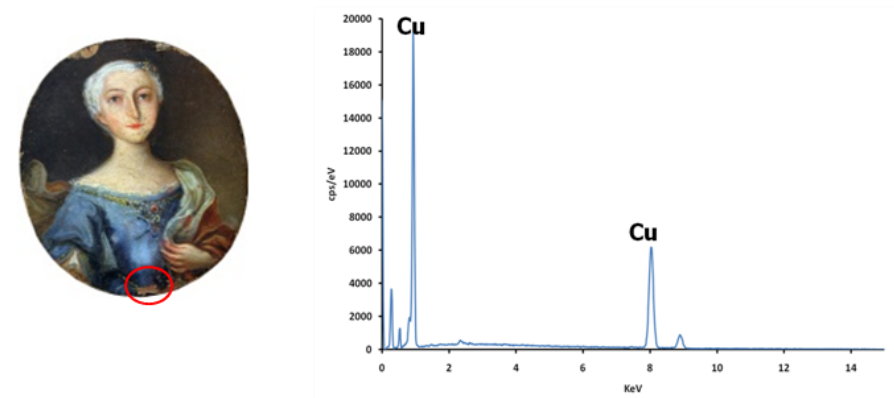

Figure 1. EDS point analysis of the copper support of miniature ME 19.

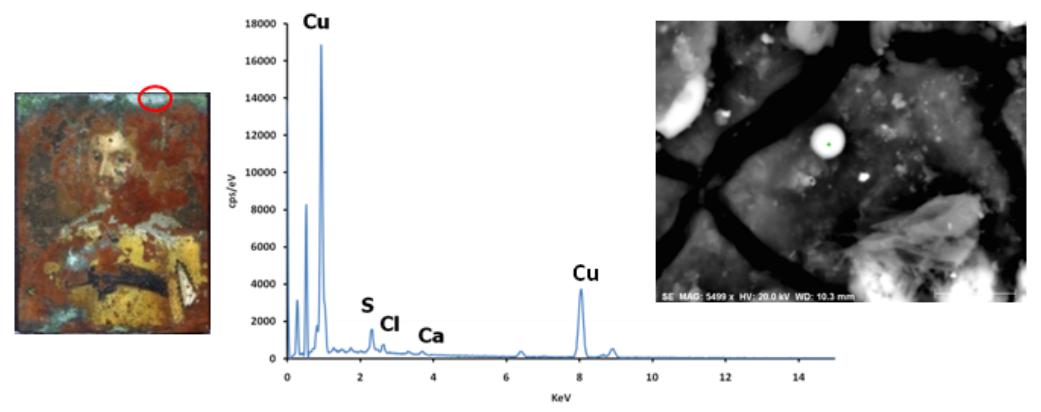

Figure 2. EDS point analysis of the corrosion products formed on the copper support of miniature ME 11.
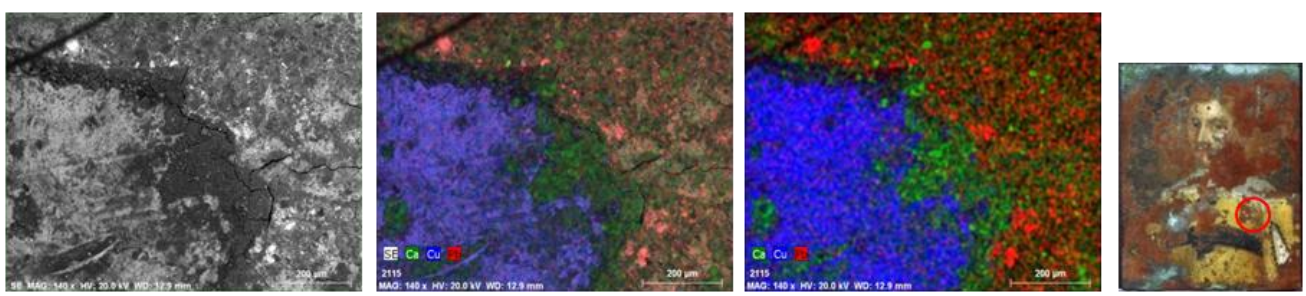

Figure 3. EDS maps of selected elements that indicated a presence of a preparatory layer between the copper support and the pictorial layer in ME 11.

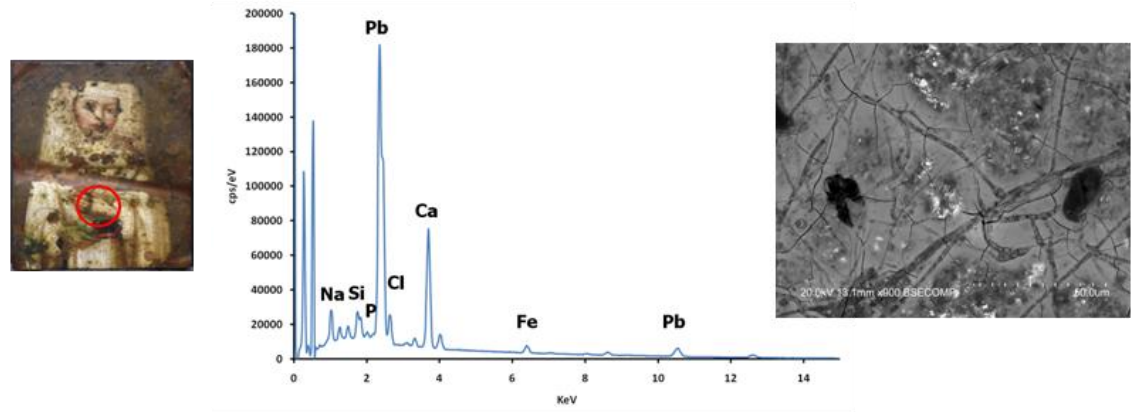

Figure 4. Observation of the lead white degradation in the carnation hand of the nun (miniature ME 641). 